\title{
Mismatch between unemployment and vacancies in the Dutch labour market
}

\author{
ROBERT A. J. DUR \\ Erasmus University Rotterdam, Tinbergen Institute, PO Box 1738, 3000 DR \\ Rotterdam, The Netherlands
}

We analyse the importance of educational mismatch between vacancies and unemployment in the Dutch labour market. Using unemployment and vacancy data by educational level, we estimate a matching function which incorporates the effect of educational mismatch on the aggregate flow of filled vacancies. Using the estimated parameters, we calculate how much of total unemployment can be attributed to educational mismatch. The results indicate that educational mismatch is not an important determinant of unemployment in the Netherlands. Moreover, it shows a remarkable trend. Contrary to common belief, the relative importance of mismatch appears to have strongly decreased since the end of the 1960s.

\section{INTRODUCTION}

Unemployment and vacancies coexist in the labour market. One reason for this phenomenon, going back to Holt (1970), is that matching vacancies and unemployed is a timeconsuming process, its efficiency being dependent on the search behaviour of both employers and the unemployed (or, more generally, job searchers). Another reason for the coexistence of unemployment and vacancies, going back to Hansen (1970), is that the characteristics of the unemployed differ from those of the jobs that are vacant. This latter reason has become known as mismatch. Both the efficiency of the matching process and mismatch may be important determinants of the level of unemployment, given the number of vacancies.

This paper analyses the importance of educational mismatch between vacancies and unemployment in the Dutch labour market. As in many Western countries, the incidence of unemployment is disproportionally high for lowereducated workers in the Netherlands, while the vacancy rate is generally lower in the lower-education segment of the labour market. For example, in 1993 the unemployment rate of lower-educated workers was more than twice as high as the unemployment rate of higher-educated workers, while the vacancy rate in the latter segment of the labour market was more than three times higher than for lowereducated workers. These data suggest that educational mismatch is important, i.e. that unemployment can be reduced by shifting some of the unemployed from the high unemployment-low vacancies segment to the low unemployment-high vacancies segment of the labour market.

In order to analyse the importance of educational mismatch between vacancies and unemployment, we use annual unemployment and vacancy data by educational level over the period 1969-93. These data have only recently become available. Adopting the model by Jackman and Roper (1987), we estimate a matching function which incorporates the effect of educational mismatch on the aggregate flow of filled job vacancies. Using the estimated parameters, we calculate how much of total unemployment can be attributed to educational mismatch for each year within the considered period.

Our paper is connected with Gorter and van Ours (1994). They study regional and occupational mismatch in the Dutch labour market by estimating a matching function using regional vacancy and unemployment data by occupation over the period 1980-88. Regional mismatch appears to be hardly present in the Dutch labour market, while the indicator of occupational mismatch included in their regression shows up insignificantly. A serious problem with analysing regional and occupational mismatch is that the labour market cannot be easily separated by region and occupation. Living in another region or having been employed in a particular sector of the economy does not preclude seeking a job elsewhere. The same criticism applies to most studies on mismatch for other countries (see e.g. the 
papers in Padoa Shioppa, 1991). This problem does not show up in analysing educational mismatch, because competition between job seekers of different eductional level appears to be absent in the Dutch labour market, at least for the categories we distinguish in our analysis (see van Ours and Ridder, 1995, for empirical evidence using the concept of the matching function). We further deviate from earlier studies by estimating a matching function which explicitly incorporates the effect of mismatch, instead of adding a more or less arbitrary mismatch-index to the matching function.

The results of our analysis indicate that educational mismatch is not an important determinant of the unemployment rate in the Netherlands. Educational mismatch only accounts for five to ten per cent of total unemployment. Moreover, it shows a remarkable trend: the relative importance of mismatch appears to have strongly decreased since the end of the 1960s. Hence, the huge rise in Dutch unemployment since the end of the 1960 s cannot be attributed to increased mismatch between vacancies and unemployment.

These results stand in sharp contrast to popular belief that increased mismatch has driven up Dutch unemployment. The alleged importance of educational mismatch is commonly based on the fact that unemployment is much higher among lower-educated workers than among highereducated workers. This, however, does not necessarily imply that aggregate unemployment would be much lower if the incidence of unemployment was more equally spread over educational categories. One reason is that vacancy rates may as well, and actually do differ between educational levels. For example, if the vacancy rate among highereducated workers is low, shifting unemployed from the lower-education segment to the higher-education segment does not tremendously increase the aggregate number of filled vacancies, and thus reduces unemployment only to a small extent. In the analysis below, we explicitly take this into account by using the matching function approach. Another reason is that the lower-educated workers constitute only a small proportion of the total labour force. During the past thirty years, the educational levels of the labour force has increased substantially. This development is reflected in a rapid decline in the share of lower-educated workers in the total labour force (from about $30 \%$ in the late 1960 s to $10 \%$ in 1993). Hence, even if unemployment among lower-educated workers could be reduced significantly by eliminating mismatch, its effect on the aggregate unemployment level is rather small.

Besides the rapid decline in the share of lower-educated workers in the total labour force, the decrease in the amount of unemployment that can be attributed to mismatch can be explained by a progressive deterioration of the labour market position of higher-educated workers. While unemployment among higher-educated workers was rare in the late 1960s (in fact, the unemployment rate among highereducated workers was close to zero), over $6 \%$ of higher- educated workers were unemployed in the early 1990s. Thus, joblessness has become a much more general phenomenon during the past decades, i.e. the importance of educational mismatch has decreased.

The paper is set up as follows. Section II gives a short description of the model adopted from Jackman and Roper (1987). Section III presents the estimation results of the matching function and compares the results with earlier research. To our best knowledge, only one earlier study exists in which a matching function is estimated using Dutch aggregate data over a fairly long time period (van Ours, 1991). Probably due to lack of data, mismatch is neglected in that paper. In Section III, we also present the development of the relative importance of educational mismatch for Dutch unemployment implied by the estimated model. Section IV concludes.

\section{THE MODEL}

In order to analyse mismatch in the Dutch labour market, we follow Jackman and Roper (1987) by using the concept of the matching function. The matching function describes the relationship between the flow of filled job vacancies in a period $(M)$ and the stocks of unemployed $(U)$ and vacancies $(V)$ at the beginning of the period (see e.g. Blanchard and Diamond, 1989, Jackman et al., 1989; and Pissarides, 1992). The location of the matching function (i.e. the efficiency of the matching process) depends on the search behaviour of both employers and job seekers. The more effective employers and job seekers search for each other (and thus the more they contact), or the higher the probability that a contact results in a match, the higher is the flow of matches given the stocks of unemployed and vacancies. In a steady state labour market, in which matchings equal the equilibrium inflow into unemployment, an increase in efficiency leads to lower unemployment and lower vacancies.

To account for possible effects of educational mismatch between unemployment and vacancies, the aggregate labour market in our model consists of a number of completely separable submarkets distinguished by educational level. Job seekers belonging to submarket $i$ cannot or do not search in other submarkets of the labour market. Consequently, a vacancy belonging to submarket $i$ is never filled by a job seeker belonging to another submarket. This assumption may be seen as quite restrictive. However, van Ours and Ridder (1995) show that competition between job seekers of different educational levels is absent in the Dutch labour market, at least for the categories we distinguish in our analysis. Assuming a Cobb-Douglas specification with constant returns to scale, the matching function for labour market segment $i$ reads:

$$
M_{i, t}=k_{t} U_{i, t}^{\alpha} V_{i, t}^{1-\alpha}
$$


where $k$ is an indicator of the efficiency of the labour market. The efficiency parameter $k$ is related to the search behaviour of employers and unemployed, which in turn may depend on the level of unemployment benefits relative to wages and the share of long-term unemployed in total unemployment. Higher benefit levels may reduce the search intensity of the unemployed because the net income gain of finding a job reduces. Moreover, unemployed may become less willing to accept a job at given wage if benefits are higher (see van den Berg, 1990, for empirical evidence using Dutch microdata). Both ways, less vacancies will be filled if unemployment benefits are higher. The share of long-term unemployed may have a negative effect on the number of filled vacancies if employers stigmatize or if long-term unemployed become discouraged. On the other hand, the benefit level in the Netherlands is generally lower for long-term unemployed than for short-term unemployed. A higher share of longterm unemployed in total unemployment thus reduces the average replacement ratio, leading to lower reservation wages, and thus more filled vacancies. Hence, the effect of the share of long-term unemployed on the number of matches is theoretically ambiguous. Forced by lack of data on filled vacancies by educational level, the efficiency parameter is assumed to be the same across segments of the labour market, as is the parameter $\alpha$. Thus, unlike the number of vacancies and unemployed, the matching process itself is assumed to be the same across submarkets (cf. Jackman and Roper, 1987, and van Ours and Ridder, 1995). ${ }^{1}$ For the same reason, we ignore employed job seekers, as is the case in most earlier theoretical and empirical research. ${ }^{2}$

The matching function on the aggregate level is found by summing up the matching functions of all segments of the labour market, which yields:

$$
M_{t}=\sum_{i} M_{i, t}=k_{t} U_{t}^{\alpha} V_{t}^{1-\alpha} \sum_{i}\left(\frac{U_{i, t}}{U_{t}}\right)^{\alpha}\left(\frac{V_{i, t}}{V_{t}}\right)^{1-\alpha}
$$

Equation 2 shows that the aggregate number of matches within period $t$ is dependent on the stocks of aggregate unemployment and vacancies, and the efficiency parameter $k$. Furthermore, the aggregate number of matches is dependent on the distribution of unemployment and vacancies over submarkets, as indicated by the last term of Equation 2. The last term is equal to one if, for each submarket $i$, the share of unemployed belonging to submar- ket $i$ in aggregate unemployment $\left(U_{i} / U\right)$ is equal to the share of vacancies belonging to submarket $i$ in aggregate vacancies $\left(V_{i} / V\right)$. Stated diferently, the segmentation of the labour market is neutral to the aggregate number of matches if and only if the number of unemployed per vacancy $(U / V)$ is equal across submarkets. This state of the labour market, in which the labour market situation is equally favourable (miserable) in each submarket, is called perfect structural balance (Jackman and Roper, 1987). If the labour market moves from perfect structural equilibrium, the last term is smaller than one, and less vacancies will be filled given the aggregate $U / V$-ratio. Consequently, aggregate unemployment will be higher than in perfect structural balance. Intuitively, if we assume two submarkets, and the number of unemployed per vacancy is very high in one segment while very low in the other, the number of filled vacancies will be lower than in perfect structural balance because the number of potential matches is low in both markets. If we could shift some of the unemployed from the high unemployment submarket to the high vacancy submarket, the aggregate number of matches would rise and unemployment and vacancies would decrease.

The difference between actual unemployment $(U)$ and unemployment in perfect structural balance $\left(U_{\mathrm{s}}\right)$ can be seen as an indicator of mismatch in the labour market (Jackman and Roper, 1987). Given the aggregate equilibrium levels of $M$ and $U / V$, which are dependent on the equilibrium inflow rate into unemployment respectively the wage formation process and (unanticipated) demand shocks, in perfect structural balance we have $M_{\mathrm{s}}=k U_{\mathrm{s}}^{\alpha} V_{\mathrm{s}}^{1-\alpha}=M$ and $U_{\mathrm{s}} / V_{\mathrm{s}}=$ $U / V$. From this and Equation 2 it follows that the difference between actual unemployment and perfect structural balance unemployment is equal to:

$$
U-U_{\mathrm{s}}=\left(1-\sum_{i}\left(\frac{U_{i, t}}{U_{t}}\right)^{\alpha}\left(\frac{V_{i, t}}{V_{t}}\right)^{(1-\alpha)}\right) U=m m U
$$

The mismatch indicator $\mathrm{mm}$ can be interpreted as the share of total unemployment that can be attributed to mismatch. ${ }^{3}$ Clearly, the importance of mismatch for the aggregate level of unemployment depends on the distribution of both the unemployed and vacancies over submarkets. Intuitively, if both unemployment and the number of vacancies are high in one submarket, and both are low in the other, shifting unemployed from the first submarket to the latter does not tremendously increase the number of filled vacancies.

\footnotetext{
${ }^{1}$ Lindeboom and van Ours (1993) examine whether the efficiency parameter $k$ differs between groups using microdata over the period 1986-88. With respect to the educational level, it appears that a higher educational level is related to lower contact probabilities, but also to a higher conditional match probability. Because $k$ is the product of these two variables, the level of $k$ does not seem to differ much between educational levels.

${ }^{2}$ Burgess (1993), Pissarides (1994) and van Ours (1995) being exceptions.

${ }^{3}$ A closely related, and better known indicator of mismatch $(m m /(1-\alpha))$ has been proposed by Layard et al. (1991), which indicates by how much unemployment would decline if mismatch was nonexistent, given the number of vacancies. Because we feel this latter assumption is unrealistic, we prefer $\mathrm{mm}$.
} 
Hence, a more equal spread of the incidence of unemployment over educational categories would not reduce unemployment to a large extent. Moreover, from Equation 3 it is clear that the influence of a submarket's developments on the level of the mismatch indicator depends on the size of the submarket. Thus, relatively high unemployment and low vacancies in a rather small submarket (e.g. the market for lower-educated workers in the early 1990s) leads to only a moderately higher level of the mismatch indicator.

\section{MISMATCH IN THE DUTCH LABOUR MARKET}

The matching function derived in the former section (Equation 2) has been estimated using annual unemployment and vacancy data for four educational levels over the period 1969-93. The four educational levels refer to:

1. primary education;

2. extended primary and lower secondary education;

3 . higher secondary education and lower vocational education;

4. higher vocational and academic education.

These data have only recently become available. Unfortunately, we lack data on the flow of filled vacancies by educational level which would enable us to estimate a matching function for each submarket. Data on the aggregate flow of filled vacancies are from vacancy surveys conducted by Statistics Netherlands (CBS) for the period 1989-93. For the period 1969-87 we calculate the aggregate flow of filled vacancies using stock data on vacancies and estimates of average vacancy durations reported in Hartog (1980) and van Ours (1991). ${ }^{4}$ More details and sources of all data used in the analysis can be found in the appendix.

According to the model presented above, mismatch between vacancies and unemployed relates to the difference between the share of unemployed belonging to segment $i$ in aggregate unemployment $\left(U_{i} / U\right)$ and the share of the vacancies belonging to segment $i$ in aggregate vacancies $\left(V_{\mathrm{i}} / V\right)$ for each segment. Figure 1a to $1 \mathrm{~d}$ show these data for the four educational levels. As is clear from this figure, the share of unemployed and the share of vacancies accounted for by a submarket are in recent years much closer to each other than they were at the end of the 1960s. This appears to be the case for each educational level. Stated differently, the labour market situation in each submarket $\left(U_{\mathrm{i}} / V_{\mathrm{i}}\right)$ resembles the aggregate labour market situation much closer now than it did twenty-five years ago. Thus, a first look at the data suggests that the relative importance of educational mismatch has decreased in the last twenty-five years. This contrasts common belief that increased mismatch, especially educational mismatch, has been one of the causes of the huge rise in Dutch unemployment.

In order to be more precise, we use the model presented in the former section to estimate how much of total unemployment can be attributed to educational mismatch in each of the years 1969-93. The empirical counterpart of Equation 2 is:

$$
\begin{aligned}
\log m_{t}= & \text { const }+\sum_{j} \lambda_{j} \log k_{j, t}+\alpha \log u_{t}+\beta \log v_{t} \\
& +(1-\zeta) \log \sum_{i=1}^{4}\left(\frac{U_{i, t}}{U_{t}}\right)^{\alpha}\left(\frac{V_{i, t}}{V_{t}}\right)^{\beta}+\varepsilon_{t}
\end{aligned}
$$

where $k_{j}$ represents a set of variables which might affect search behaviour of unemployed and employers, such as the replacement rate and the share of long-term unemployed in total unemployment (see Section II). Furthermore, we took up a time trend to account for changes in search behaviour related to unobserved variables. The error term $(\varepsilon)$ is assumed to have the usual characteristics. The lower-case letters of $M, U$, and $V$ indicate that we have normalized these variables with the size of the labour force (cf. van Ours, 1991). Note that we initially do not enforce constant returns to scale, nor a unitary coefficient for the mismatch index. Because of possible simultaneity, we estimated Equation 2 using (nonlinear) two-stage least squares, treating the unemployment rate, the vacancy rate and the share of long-term unemployed as endogenous. Besides the exogenous and lagged endogenous variables included in the model, as additional instruments were used the logs of the capacity utilization, the tax wedge, consumer minus producer prices, the size of the working-age population and the capital stock. The estimation results are presented in Table 1.

The estimation results are quite satisfactory. The first column presents the results of the unrestricted estimation. The sum of the estimated values of $\alpha$ and $\beta$ is close to one, indicating constant returns to scale. An $F$-test revealed that the hypothesis of constant returns to scale cannot be rejected $(F=0.03)$. Hence, in the second estimation, we restricted the sum of $\alpha$ and $\beta$ to be equal to one. The coefficient for the mismatch index appears to be insignificantly different from its theoretical value of one, ${ }^{5}$ and is set at unity in the second estimation. The share of long-term unemployed shows up insignificantly, and is dropped in the second estimation. This result in not too surprising, since the sign of this coefficient is theoretically ambiguous.

Column two presents the estimation results of the restricted and most preferred specification. The results are close to those obtained by van Ours (1991), which is,

\footnotetext{
${ }^{4}$ The latter data have been estimated using the method described in van Ours and Ridder (1991).

${ }^{5}$ This result does not change if we omit the dummy variable and the proportion of long-term unemployment as explanatory variables. The hypothesis that the coefficient for the mismatch index is equal to one cannot be rejected at conventional levels $(t=0.75)$.
} 
Educational level 1

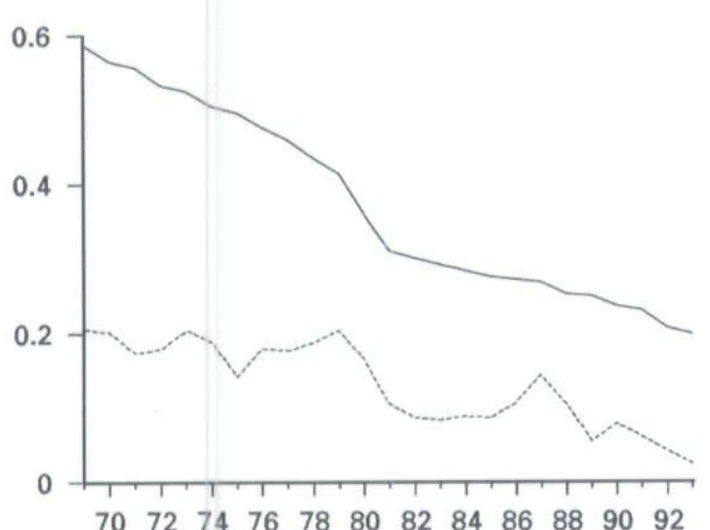

(a)

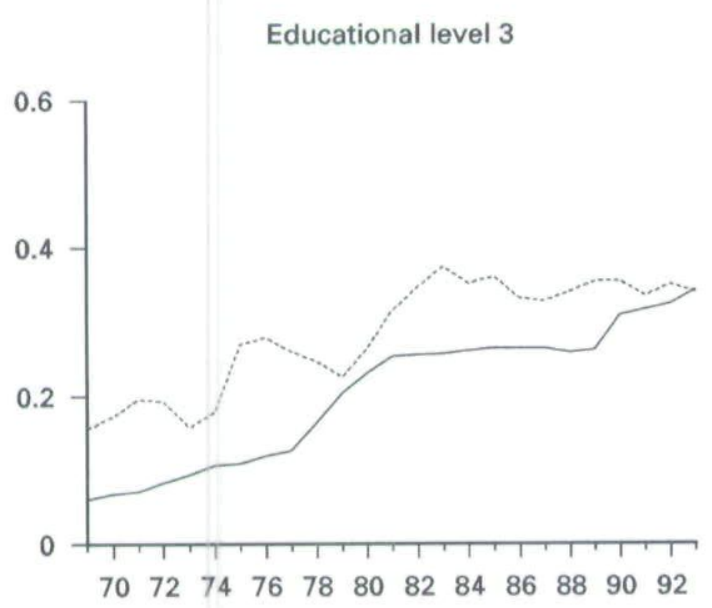

(c)
Educational level 2

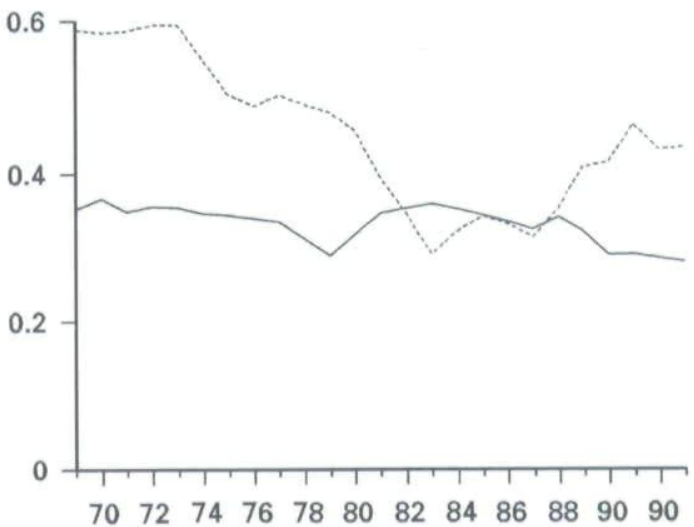

(b)

\section{Educational level 4}

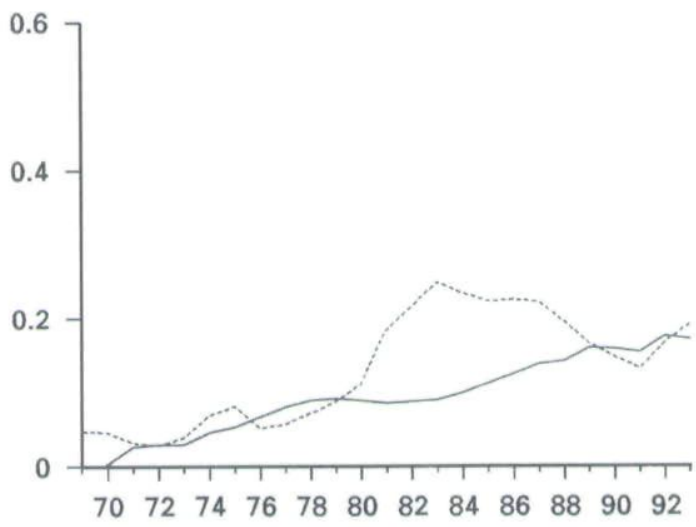

(d)

Fig. 1(a)-(d). Share of unemployed (-) (vacancies (.......)) in total unemployment (vacancies) of four educational levels

Table 1. Estimation results matching function

\begin{tabular}{lcc}
\hline & Unrestricted estimation & Restricted estimation \\
\hline Constant & $2.84(0.38)$ & $6.77(3.17)$ \\
$\log$ (replacement rate) & $-1.77(3.19)$ & $-2.25(4.62)$ \\
$\log$ (share of long-term unemployed) & $0.16(1.42)$ & - \\
Dummy 1977-93 & $-0.25(2.16)$ & $-0.12(1.81)$ \\
$\alpha$ & $0.35(1.88)$ & $0.40(14.87)$ \\
$\beta$ & $0.60(5.45)$ & $0.60(-)$ \\
$\zeta$ & $0.36(0.18)$ & - \\
$R^{2}$ & 0.90 & 1.83 \\
Durbin-Watson statistic & 2.32 & $1969-93$ \\
Estimation period & $1969-93$ & \\
\hline
\end{tabular}

Note: Absolute $t$-values in parentheses. $R^{2}$ corrected for degrees of freedom.

according to our best knowledge, the only other study in which a matching function is estimated using Dutch aggregate data over a fairly long time period. ${ }^{6}$ The estimated value of $\alpha$ of 0.40 is close to the estimate obtained by van Ours of
0.37. Conform to our results, he finds constant returns to scale. Constant returns to scale is also found in most studies using UK and US data (see Coles and Smith, 1996, and the references cited therein). In contrast to van Ours, we do not

${ }^{6}$ Van Ours' estimation period is 1961-87. The reason why our estimation period starts at 1969 instead of 1961 is that the unemployment and vacancy data by educational level are only available from 1969 onwards. 


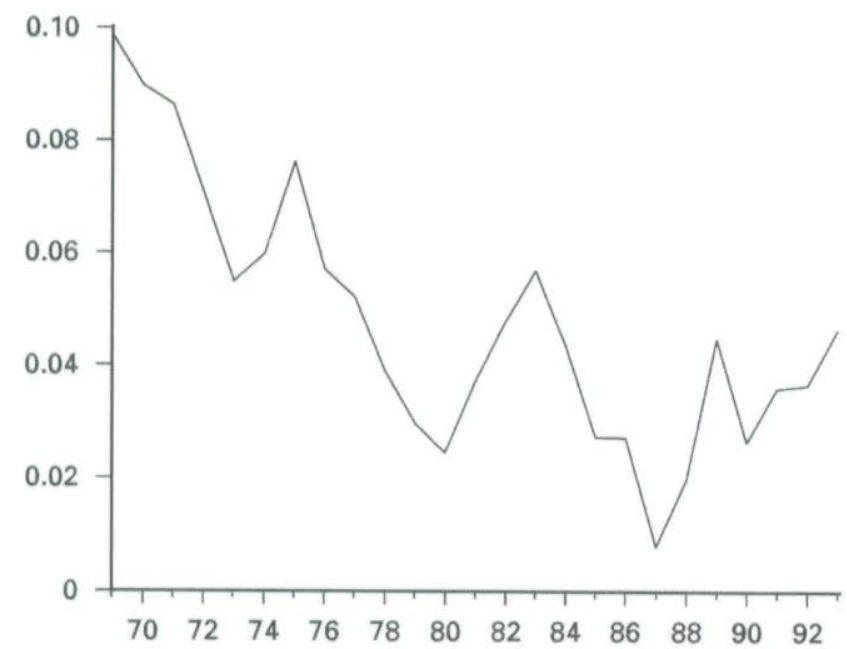

Fig. 2. Share of total unemployment attributed to educational mismatch (1969-1993)

find a negative effect of the share of long-term unemployed, ${ }^{7}$ while we find much stronger effects of the replacement rate on the number of matchings. Further, we deviate from van Ours' results with respect to the time trend variable. We tried several time trend variables, from which one appeared to be significant. The estimated coefficient implies that the efficiency of the matching process has decreased since 1977. In contrast, van Ours observes no shift in the matching function over the period 1970-87. However, it should be noted that the influence of the time trend variable in our estimation is very small in comparison with the influence of the replacement rate. A quick look at the development of the efficiency parameter $k$ as implied by the estimated model reveals that the time trend variable hardly affects the pattern of $k$.

Having estimated the parameters of Equation 2, we can now calculate how much of total unemployment can be attributed to educational mismatch, for each year within the considered period, according to the estimated model (see Equation 3). Figure 2 shows how the mismatch parameter $\mathrm{mm}$ implied by the estimated model developed during the considered period. Educational mismatch appears to explain only $5-10 \%$ of total unemployment. Moreover, it shows a remarkable trend. As already suggested by Fig. 1(a)-(d), the relative importance of educational mismatch appears to have strongly decreased since the end of the 1960s. Hence, in contrast to common belief, the huge rise in the Dutch unemployment rate over the past 25 years cannot be explained by increased educational mismatch between unemployment and vacancies. ${ }^{8}$

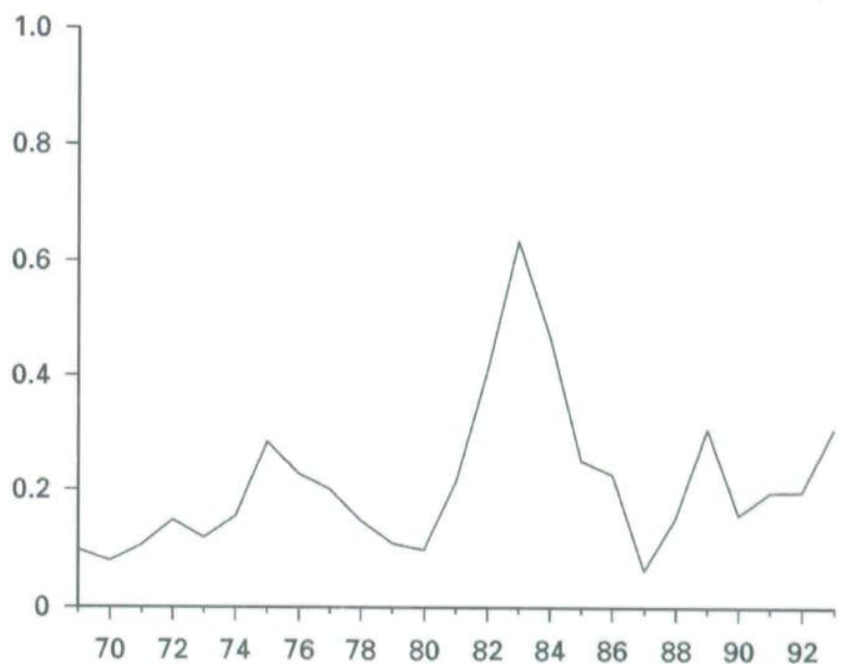

Fig. 3. Unemployment attributed to educational mismatch as a percentage of the labour force (1969-1993)

Because the Dutch unemployment rate hugely increased during the period under consideration (from approximately $1 \%$ at the end of the $1960 \mathrm{~s}$, to more than $11 \%$ in the mid-1980s and $7 \%$ in the early 1990 s), the absolute amount of unemployment due to educational mismatch shows a somewhat different pattern than the relative share reported in Fig. 2. Following Equation 3, the amount of unemployment that can be attributed to educational mismatch is equal to the mismatch indicator $\mathrm{mm}$ times the unemployment rate $u$. The resulting data are shown in Fig. 3. No clear trend can be detected in these data. The huge rise in the aggregate unemployment rate makes that the absolute amount of unemployment due to educational mismatch has remained stable, although the relative importance of educational mismatch has strongly decreased. Note again that educational mismatch is not a very important determinant of Dutch unemployment. If mismatch between unemployment and vacancies would be absent in the Dutch labour market, the unemployment rate would decrease with merely 0.1 to 0.3 percentage point.

A final note concerns the cyclical pattern of the mismatch indicator. The pattern of mismatch appears to be countercyclical. ${ }^{9}$ Thus, mismatch increases during recessions and decreases during booms. This can possibly be explained by the dismissal behaviour of employers. If lower-educated workers acquire less firm-specific skills than highereducated workers, employers may first dismiss the easier replaceable lower educated workers during cyclical downturns

${ }^{7}$ Our result is, however, consistent with Gorter and van Ours (1994) using Dutch regional data over the period 1980-88 and Blanchard and Diamond (1989) for the US labour market.

${ }^{8}$ An empirical analysis of some alternative explanations for the rise in Dutch unemployment can be found in Dur (1996).

${ }^{9} \mathrm{~A}$ simple regression of $\mathrm{mm}$ on a trend and the capacity utilization grade yields: $\mathrm{mm}=-0.003$ trend $-0.24 \log$ (capacity utilization grade). 
(van Ours and Ridder, 1995). ${ }^{10}$ This creates more variation in the unemployment rate between educational levels during cyclical downturns, and thus increases educational mismatch.

\section{CONCLUSIONS}

In this paper, we analysed the importance of educational mismatch in the Dutch labour market. Using annual unemployment and vacancy data by educational level over the period 1969-93, we estimated a matching function which incorporates the effect of educational mismatch on the aggregate flow of filled job vacancies. Using the estimated parameters, we calculated how much of total unemployment can be attributed to educational mismatch for each year within the considered period.

The results of our analysis indicate that educational mismatch is not a very important determinant of the unemployment rate in the Netherlands. Only 5-10\% of total unemployment can be attributed to educational mismatch. If mismatch would be absent in the Dutch labour market, the unemployment rate would decrease with merely 0.1 to 0.3 percentage point.

The pattern of educational mismatch shows a remarkable trend over the considered period. Contrary to common belief, the relative importance of educational mismatch appears to have strongly decreased since the end of the $1960 \mathrm{~s}$. Thus, the huge rise in Dutch unemployment since the end of the 1960 s cannot be accounted for by increased educational mismatch between vacancies and unemployment.

\section{ACKNOWLEDGEMENT}

I am grateful to an anonymous referee for helpful comments on an earlier version of this paper.

\section{REFERENCES}

Blanchard, O. J. and Diamond, P. (1989) The Beveridge curve, Brookings Papers on Economic Activity, 1, 1-60.

Burgess, S. M. (1993) A model of job competition between unemployed and employed job searchers: an application to the unemployment outflow rate in Britain, Economic Journal, 103(420), 1190-204.

Coles, M. G. and Smith, E. (1996) Cross-section estimation of the matching function: evidence from England and Wales, Economica, 63(252), p. 589-97.

Dur, R. A. J. (1996) Explaining unemployment trends in the Netherlands, Ocfeb Research Memorandum 9609, Rotterdam.
Gorter, C. and van Ours, J. (1994) Matching unemployment and vacancies in regional labor markets: an empirical analysis for the Netherlands, Papers in Regional Science, 73(2), 153-67.

Hansen, B. (1970) Excess demand, unemployment, vacancies and wages, Quarterly Journal of Economics, 84(1), 1-23.

Hartog, J. (1980) Tussen Vraag en Aanbod, Stenfert Kroese, Leiden.

Holt, C. C. (1970) How can the Phillips curve be moved to reduce both inflation and unemployment? in Microeconomic Foundations of Employment and Inflation Theory (Eds) E. S. Phelps, A. A. Alchian and C. C. Holt, Nolton, New York, pp. 224-56.

Jackman, R. and Roper, S. (1987) Structural unemployment, Oxford Bulletin of Economics and Statistics, 49(1), 9-36.

Jackman, R., Layard, R. and Pissarides, C. (1989) On vacancies, Oxford Bulletin of Economics and Statistics, 51(4), 377-94.

Layard, R., Nickell, S. and Jackman, R. (1991) Unemployment; Macroeconomic Performance and the Labour Market, Oxford University Press, Oxford.

Lever, M. H. C. and van der Linden, A. S. R. (1996) Demand for and wages of high- and low-skilled labour in the Netherlands, EIM Research Report 9607, Zoetermeer.

Lindeboom, M. and van Ours, J. (1993) Macro matching and micro search durations: looking inside the black box of job formation, in Panel Data and Labour Market Dynamics, (Eds), H. Bunzel, P. Jensen and N. Westergård-Nielsen, Elsevier Science Publishers, Amsterdam, pp. 1-20.

Padoa Schioppa, F. (Ed.) (1991) Mismatch and Labour Mobility, Cambridge University Press, Cambridge.

Pissarides, C. (1992) Search theory at twenty-one, CEP Discussion Paper 90, London.

Pissarides, C. (1994) Search unemployment with on-the-job search, Review of Economic Studies, 61(3), 457-75.

Van Ours, J. C. (1991) The efficiency of the Dutch labour market in matching unemployment and vacancies, De Economist, 139(3), 358-78.

Van Ours, J. C. (1995) An empirical note on employed and unemployed job search, Economics Letters, 49(4), 447-52.

Van Ours, J. C. and Ridder, G. (1991) Cyclical variation in vacancy duration and vacancy flows: an empirical analysis, European Economic Review, 35(5), 1143-55.

Van Ours, J. C. and Ridder, G. (1995) Job matching and job competition - are lower educated workers at the back of the job queues? European Economic Review, 39(9), 1717-31.

Van den Berg, G. J. (1990) Nonstationarity in job search theory, Review of Economic Studies, 57(2), 255-77.

\section{APPENDIX: DATA SOURCES}

$U=$ aggregate number of registered unemployed. Source: CBS, Statistiek geregistreerde werkloosheid.

$U_{i}=$ number of unemployed by educational level. Source: CBS, Tijdreeksen arbeidsrekeningen 1969-1993.

$V=$ aggregate number of vacancies. Source: CPB, Centraal Economisch Plan.

$V_{i}=$ number of vacancies by educational level. Source: CBS, Tijdreeksen arbeidsrekeningen 1969-1993.

\footnotetext{
${ }^{10}$ Some additional indirect evidence for this hypothesis can be found in Lever and van der Linden (1996). Based on estimation of labour demand equations differentiated by educational level, they find that adjustment of demand for lower-educated workers evolves more rapidly than demand for higher-educated labour.
} 
$M=$ aggregate flow of filled vacancies. Sources: 1969-1988; $V / T_{v}, 1989-1993$ : CBS, Sociaal Economische Maandstatistiek, March 1997, p. 40.

$T_{v}=$ average vacancy duration. Sources: 1969-1978: Hartog (1980), 1979: interpolation, 1980-1987: van Ours (1991), 1988: interpolation, 1989-1993 calculated as $V / M$.

$L=$ aggregate labour force. Source: CPB, Centraal Economisch Plan.
$L t u=$ share of long-term unemployed in total unemployment. Sources: 1969-1987: van Ours (1991), 1988-1993: CBS, Statistiek geregistreerde werkloosheid. $R R=$ replacement rate $=$ minimum benefit level $/ 0.8 \times$ average wage. Source: CPB, Centraal Economisch Plan. Instrument variables. Sources: OECD, Economic Outlook, and CPB, Centraal Economisch Plan. 
Copyright of Applied Economics is the property of Routledge, Ltd.. The copyright in an individual article may be maintained by the author in certain cases. Content may not be copied or emailed to multiple sites or posted to a listserv without the copyright holder's express written permission. However, users may print, download, or email articles for individual use. 